\title{
Study of the effect of burrows of European Badgers (Meles meles) on the initiation of breaching in dikes
}

\author{
Maria Luisa Taccari $^{1, a}$ and Raymond van der Meij ${ }^{2}$ \\ ${ }^{1}$ Delft University of Technology, Civil Engineering, 2628 CD Delft, Netherlands \\ ${ }^{2}$ Deltares, 2629 HD Delft, Netherlands
}

\begin{abstract}
Levees offer an ideal environment for the diffusion of European Badgers (Meles Meles), whose burrowing activity can be a main cause of breaching in dikes. This paper evaluates the contribution of burrows dug by badgers to the initiation of a dike failure. For example, a breach in a dike near Modena (Italy), where animal burrowing activity was active, took place on the 19th January 2014. While the distribution of the underground system inside the dike is usually unknown, the burrow entrances are easily identified along the slopes. Different scenarios of burrow entrances located along the outer and inner slope are considered and their contribution to sliding of the inner slope, microinstability and internal erosion is investigated. The most dangerous positions of entrances for the stability of the dike are assessed and presented.
\end{abstract}

\section{Introduction}

European Badgers are medium-sized omnivorous with nocturnal life habits. They live in Europe and eastern Asia, in clans, that are family groups up to 12 members.

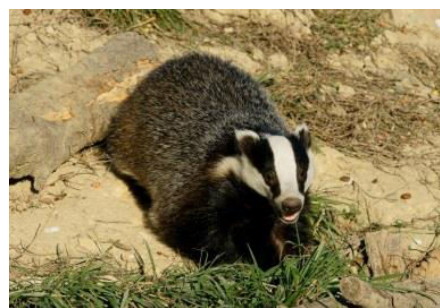

Figure 1 European badger (Meles meles).

The considered animal burrows are the tunnels excavated by the European badgers into the ground. They create complex systems called setts, which are mostly located at low altitude and in steep slopes, preferably with cover. Most of the setts are constructed in loam, sandy and clay soils. The preference for sandy and dry soils is justified by the fact that they are more friable and thus it is easier to dig in them (Kruuk 1978 ; Reid et al. 2008). The presence of setts is facilitated by vegetation cover, slope and diggable soil. The vegetation protects them, the roots provide structural support to the tunnel system and facilitate the drainage. Also, slopes can improve drainage, keeping the setts dry (Byrne et al. 2012).

\footnotetext{
${ }^{\mathrm{a}}$ Corresponding author: MariaLuisa.Taccari@deltares.nl
}

Piping resulting by animal holes was observed in Arizona, along the San Pietro River(Carrol, 1949). The pipes which are created by gophers erode becoming huge tunnels which connect to the main one. On 5 January 2008, a failure occurred in the Truckee Canal (Fernley, Nevada). The post-investigation revealed that the flow rates were not exceptional and that the extensive network constructed by animals would have caused piping to occur (Paul \& Slaven, 2009). Other historical failure caused by internal erosion due to animal burrowing are the followings (Richards \& Reddy, 2007): Big Sand Creek Str Y032032, MS (1996), Lower Stichcomb, GA (1978), Mallard Lake, TN (1996) and Prospect Reservoir Dam, CO (2002).

The recent failure of the levee of San Matteo (Modena, Italy) on 19th January 2014 is most likely also due to the contribution of European Badgers, Foxes and Crested Porcupines (L. D'Alpaos et al). The post-event analyses revealed that internal erosion was the likely mechanism leading to failure. The underground system dug by the animals consisted of connected tunnels between the outer to the inner slope. When the water level in the river Secchia overcame the entrance of the burrows at the inner slope, water filled the burrows and starting eroding them, till collapse occurred. (Taccari \& van der Meij)

These recent events and the little guidance and literature available on the topic underline the importance of the investigation into the subject. The current paper investigates the contribution of animal burrows created by European Badgers to Macro-Instability, internal erosion and Micro-Instability. European badgers and 
Crested Porcupines create similar underground systems, which they often share with Red Foxes. Thus, the conclusions of the paper can be generalized also to the burrows created by these animals.

The paper aims to give guidelines for the definition of the most dangerous underground systems for the three mentioned failure mechanisms. A proper field survey, which can recognise the critical entrances of the burrows and networks, and successive interventions can reduce the risk of flooding.

\section{Failure modes}

A flood defence can fail due to several possible failure mechanisms (Figure 22).
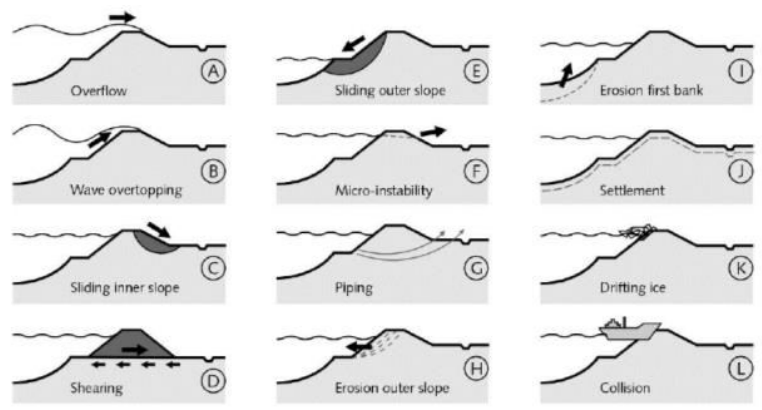

Figure 2. Possible failure mechanism of flood defences. (Jonkman and Schweckendiek, 2015).

Overflow and wave overtopping are failure mechanisms related to the hydraulic boundary conditions. Shearing is due to the horizontal forces exercised by the water in the river. Erosion of the foreshore, settlement, drifting ice and collision by vessels aren't caused by animal burrows. Finally, badgers tend to dig along the dry inner slope; for this reason the problems of erosion of the outer slope and sliding of the outer slope, which mainly happens due to a sudden drop of the external water level, are not considered in the current paper.

The failure modes which are investigated in relation to burrowing activities are macro-instability, internal erosion and micro-instability.

\subsection{Macro-Instability}

\subsubsection{Introduction}

Instability occurs when actual shear stress exceeds the shearing resistance along a plane, where failure will thus happen. Instability occurs when actual shear stress exceeds the shearing resistance along a plane, where failure will consequently happen.

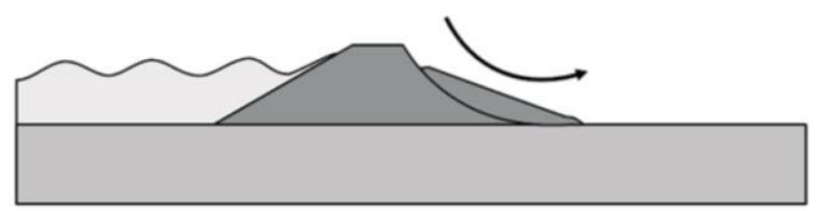

Figure 3 Instability of the inner slope.
The infiltration of water into the soil body, due to rainfall or increase of water load acting on the levee, changes the pore water pressure inside the dike body. As the pore water pressures inside the levee increase, the effective stresses $\sigma^{\prime}$ decrease, according to Terzaghi's law. The decrease of effective stresses causes the decrease of shear strength (Reddi, 2003). Moreover, the saturation of the soil due to the infiltration of water increases the soil weight, which also contributes to the driving moment and thus increase the probability of instability.

\subsubsection{Influence of animal burrows}

When the water level in the river increases, the phreatic line changes with with a certain speed, depending on the properties of the soil body. The heterogeneity introduced by the animal burrows influences its trend such as Figure 44 illustrates.

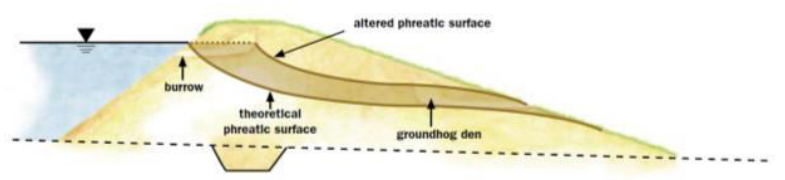

Figure 4 Shortening of seepage path due to animal burrow ("Diagnosis of urban flood embankment performance," 2012).

The animal burrows can reduce the seepage length and the phreatic line can rise, increasing the risk of dike instability. According to a study performed by Deltares ("Diagnosis of urban flood embankment performance," 2012), the burrows created by badgers can reduce the seepage length up to 6 meters.

\subsection{Internal Erosion}

\subsubsection{Introduction}

Internal Erosion is named a particular mechanism belonging to the more generic family of "piping", (Richards \& Reddy, 2007) for which the soil particles are removed by tractive forces along pre-existing openings such as cavities or voids. The most favourable soil to internal erosion is highly erodible, permeable and loosely compacted. Silts and silty sands with low clay content, generally with low dry density, high void ratio and collapsing properties are the most susceptible soils to piping (Masannat, 1980).

\subsubsection{Influence of animal burrows}

Since the soil type for which internal erosion can occur corresponds to the diggable soil chosen by the animals for the burrowing activities, particular attention has to be posed to this failure mode. As a matter of fact, internal erosion leads most likely to several historical 
cases, such as the failure of the levee of San Matteo (Taccari \& van der Meij) and the one occurred in the Truckee Canal (Fernley, Nevada). The post-investigation revealed that the extensive network constructed by animals would have caused piping to occur (Paul \& Slaven, 2009). Water, entering and flowing through the cavities, would have act at high pressures against the tunnels, creating hydraulic fractures throw the levee and opening other seepage paths. The resulting piping and erosion would have thus leaded to failure.

\subsection{Micro-Instability}

\subsubsection{Introduction}

Micro-instability occurs when there is a seepage point above the inner toe and the forces created by the flow exceed the resisting shear resistance. (Vorogushyn, Merz, $\&$ Apel, 2009). The process starts at the exit point, where particles are detached and flushed away by the seepage flow, and then retrocedes towards inner slope.

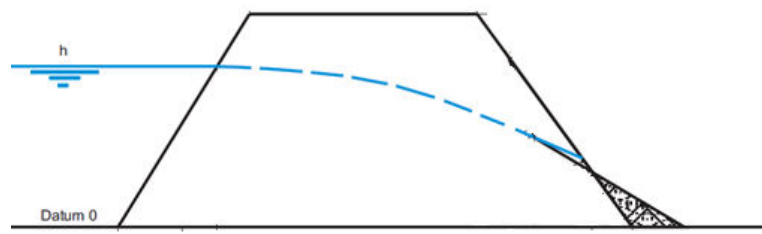

Figure 5 Slope failure due to micro-instability (Vorogushyn et al., 2009).

\subsubsection{Influence of animal burrows}

Non cohesive soil, erodible material and unprotected exit are favourable conditions for the development of micro-instability. Thus, the diggable soil chosen by badgers for their underground systems can constitute a problem also when considering this failure mechanism.

Since the presence of animal burrows can rise the phreatic line, if it exits above the inner toe of the dike and the seepage forces are high enough, the probability of seepage and micro-instability increases.

\section{Underground systems}

\subsection{Setts}

The setts can be used by more clans and they consist on complex underground systems, which are composed by several passages and chambers. The central part is constituted by a main sett, occupied by most of the colony's members. Close to it, $50 \mathrm{~m}$ up to $150 \mathrm{~m}$ far away, there are non-main setts, which can further divided into annexe, subsidiary and outlier setts, depending on the frequency of use and the connectivity with the main set. Outlier setts are not often occupied and they have only one entrance; annex setts, which are close to the main sett, have few entrances and are usually occupied; subsidiary setts, which are far from the main sett, have many entrances and are sometimes occupied. One sett can have between 1-2 and 44-50 entrances, among which some can be very used and other abandoned. The factors that affect the size and complexity of the sett are its function, the soil type and its age. In particular, main setts are larger than annexes, subsidiary and outliers setts; more the soil is diggable and more the system is developed; finally oldest systems are the biggest and most complex.
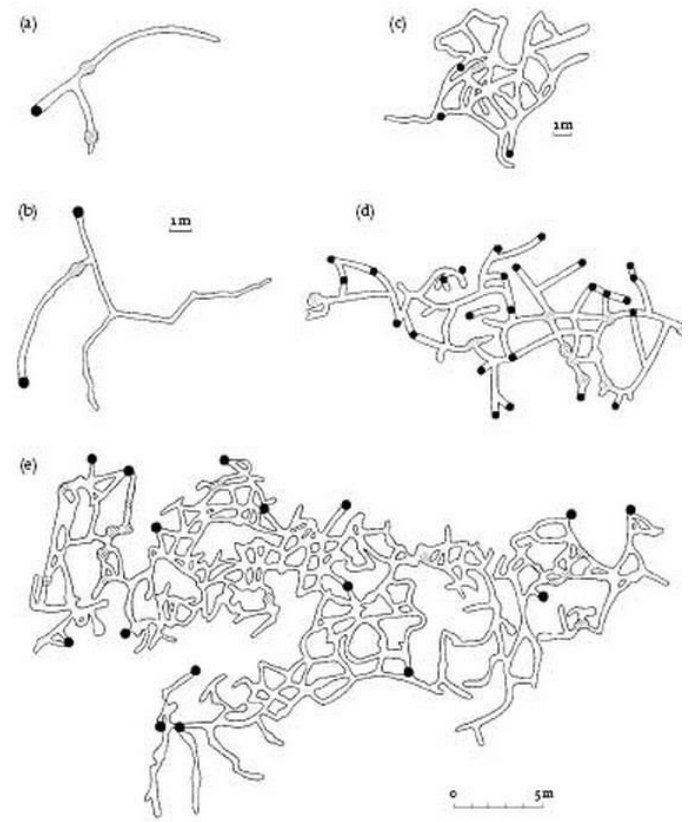

Figure 6 Schematization of badgers setts of different size and complexity: outlier setts (a and b), subsidiary sett (d) and main setts (c and e). The entrances are indicated by the filled circles. (Roper, 2010).

\subsection{Burrows geometry}

Despite of the complexity of the underground systems, some geometrical patterns do repeat in every sett. The burrows of badgers are tunnels with semicircular (arched) or squashed elliptical form, wider than higher(Heptner \& Sludskii, 1988). The tunnels have typical height of $0.20 \mathrm{~m}$ and are $0.30-0.35 \mathrm{~m}$ wide (Nichol, Lenham, \& Reynolds, 2003). The nesting chambers have squashed spherical shape with arched roof and their horizontal section is roughly circular (Roper, 2010). The dimensions of the chamber can be wider if more badgers occupy it.

At least one entrance of the burrows is higher than the others in order to promote ventilation to the chambers and the entrance tunnels are inclined to ensure drainage. The tunnels usually don't go deeper than 1 meter underneath the entrance and they are located in a dry place above the groundwater level. The tunnels initially go down (with an inclination of $40-45^{\circ}$ ) but they can also run horizontally. If then the same soil is present, the depth of tunnel systems is approximately constant. Two tunnels intersect at $90^{\circ}$, while three tunnels at $120^{\circ}$. They can split in separate chambers, which are usually situated at the end of the burrows (5-10 meters from the opening entrance) or are a widening of the tunnels themselves. 


\subsection{Development of system with time}

The enlargement of the sett is typically a function of several factors, such as the sett age, the size of the social group using the sett, the change in the size of the social group and the soil characteristics (Roper, 2010).

By using data from badger setts in Wytham Woods, Oxfordshire, UK, M.A. Coombes and H. A. Viles developed a model to correlate the population dynamics and the zoogeomorphic activity (Coombes \& Viles, 2015). The surface area, defined as the "extend of existing mounds and spoil", and the volume that has been excavated in the subsurface are correlated to factors such as the minimum number of years for which the sett exists, the number of excavation years (years of residency of the badgers in the sett), the sett fecundity (number of cubs) and the number of adults resident in the sett. Moreover, according to Roper (2010), the average growing rate of badger setts is one entrance every two year.

\subsection{Estimation of the likely underground system}

The distribution of the tunnels and chambers in the underground system can be estimated by knowing the burrow entrances, the excavated volume and the likely geometry of the underground system. The entrances are localized by site investigation or aerial photos while the excavated volume can be assumed through the correlation of population dynamics and zoo-geomorphic activity. Through the knowledge of the recurrent patterns described by literature review or by field investigation, scenarios for the likely underground system occurring in the specific location can be defined.

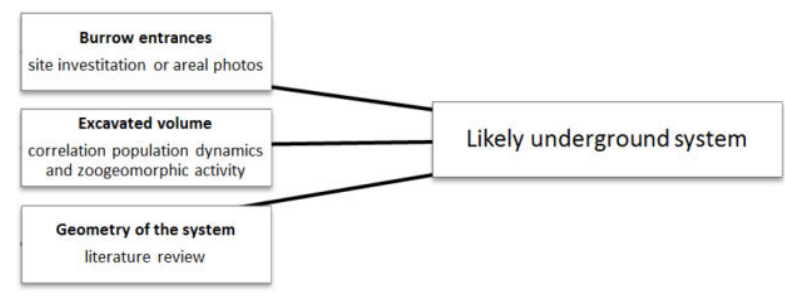

Figure.7. Estimation of underground system, by knowledge of burrow entrances, excavated volume and geometry of the system.

\section{Influence of animal burrows on failure modes}

\subsection{Analyses}

The evaluation of the effects of burrows geometry on the failure mechanisms has been carried out by considering the failure of the levee along the Secchia river as case study (Taccari \& van der Meij).

In order to investigate the effects of burrows for macro and micro-instability, analyses with the software PLAXIS 2D and 3D are performed. Several scenarios of tunnels and burrows entrances (position and number) are simulated, through the implementation of burrows as high permeable and porous soil.

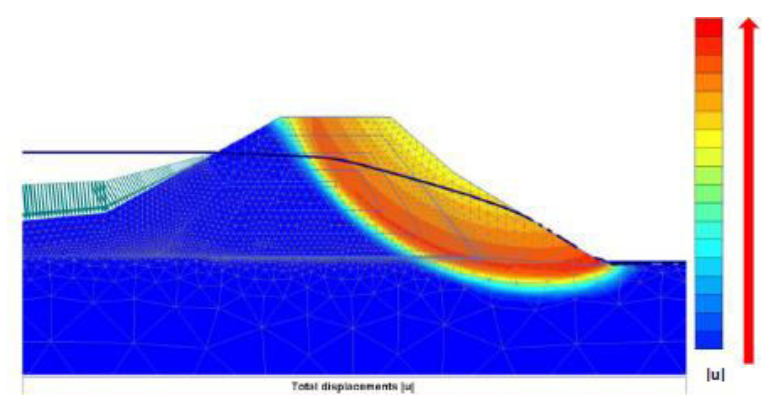

Figure 8 Example of calculation performed with PLAXIS 2D.

Internal Erosion is instead analysed with a simplified analytical method proposed by Bezzazi et all (Bezzazi et al., 2010) which estimates the evolution of the inner tube radius as a function of time.

The conclusion derived by this case study are generalized and presented in the following paragraphs.

\subsection{Effect of different positions of burrows}

\subsubsection{Macro-Instability}

Burrows located at the outer slope increase the probability of instability of the inner slope by raising the pore pressures and so decreasing the effective stresses inside the dike body. Their effect increases as their entrance along the outer slope is deeper. Burrows with entrance along the upper part of the slope do not affect the results (case 1 in Figure 99). Lower burrows (case 2) intercept the phreatic line and increase the pore water pressures, so decreasing the effective stresses and the shear resistance. As a consequence, the safety factor (SF) reduces compared to the case of no burrow. Finally, SF significantly reduces as the entrance is below the reached water level (case 3).

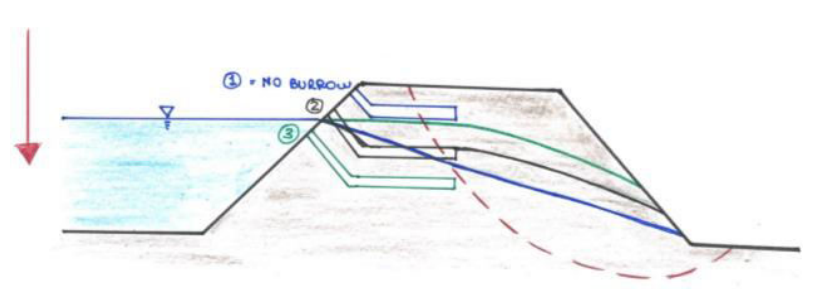

Figure 9. Influence of animal burrows with entrance along the outer slope to macro-instability of the inner slope. The sliding surface is indicated by the red dashed line.

The presence of a burrow at the inner slope can have different effects on macro-stability according to its position. If the entrance is located in the upper part of the inner slope (case 1), the factor of safety is not influenced by the presence of the burrow. If the burrow intercepts the water level and raise the values of pore pressure inside the dike body (case 2), the additional weight of water and the raise of water pressures contribute to the sliding and so decrease the factor of safety.

A burrow with entrance at the lower part of the inner slope (case 3) can increase the SF for macro-stability compared to the case without any burrows or with 
entrances at the outer slope. As a matter of fact, it acts as a drain, by lowering the water table in the centre of the levee and so reducing the pore pressures. As a consequence the resistance shear strength along the sliding plane (red dashed line in Figure 1010) increases and so also the factor of safety.

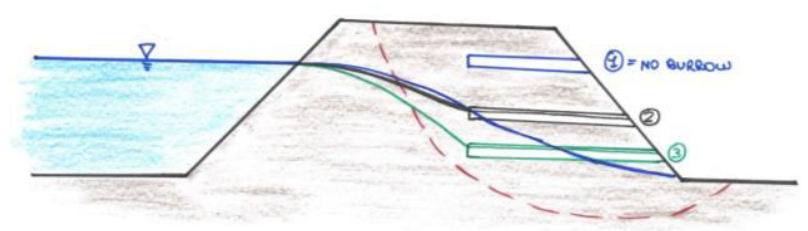

Figure 10 Influence of animal burrows with entrance along the inner slope to macro-instability of the inner slope. The sliding surface is indicated by the red dashed line.

\subsubsection{Internal Erosion}

Internal Erosion was the leading failure mechanism leading to the failure along the Secchia river, such as the cause of several historical cases previously mentioned. Therefore, particular attention must be given to this failure mode, which can be regarded as the most dangerous mechanism produced by a burrowing system connecting inner and outer slope.

Several conditions must be met so that burrowing networks can cause Internal Erosion. First of all, as represented by the underground system in Figure 1111, the entrance of the burrow along the outer slope is placed below the reached water level so that water enters and completely fills the tunnel. Since the development of internal erosion depends on the difference of pressure between the inner and outer side, lower is the burrow at the outer slope and more time it is placed below the water level for transient flow conditions, higher is the risk of internal erosion.

Second, the burrow is connected to the inner slope, so that water flows from the outer to the inner slope, exercising erosive forces along the tunnel surface. Internal erosion is facilitated by shorter tunnels. For this reason, the most danger is represented by burrows going from the outer directly to the inner slope, with the shortest distance between the entrances.

Finally, the most important factor contributing to Internal Erosion is given by the ease of erosion. In particular, animals excavate in erodible and diggable soil, which is so also prone to internal erosion.

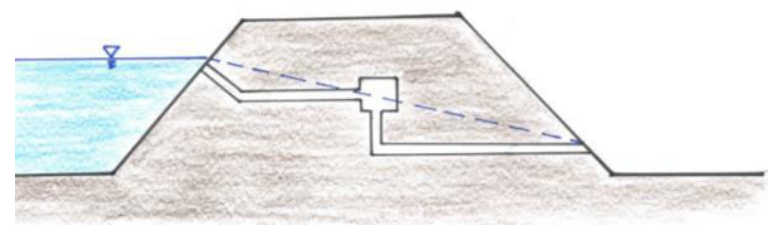

Figure 11 Burrowing network which can cause Internal Erosion.

\subsubsection{Micro-Instability}

The presence of burrows can affect Micro-instability. Burrows with entrance along the outer slope can increase the probability of micro-instability to occur. If they are located in the upper part of the dike and they do not intercept the phreatic line (case 1 in Figure 1212), their influence is null and the probability of micro-instability is equal to the case of no burrow. As the entrance is lower, micro-instability can occur: lower burrows increase the pore water pressures, so that the phreatic line presents higher exit point along the inner slope (case 2 and 3 ).

Finally, if the phreatic line exits below the inner toe when no burrows are present, the introduction of cavities can lead to an exit point along the inner slope so that micro-instability can occur. As the burrow entrance along the outer slope is lower, the resulting exit point is higher so increasing the risk of micro-instability.

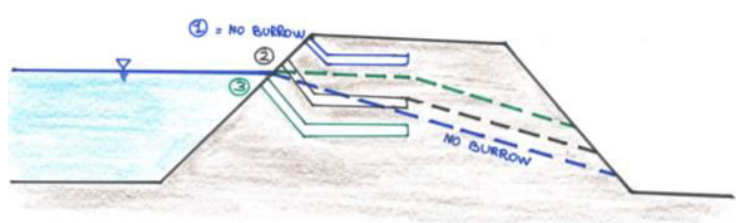

Figure 12 Influence of animal burrows with entrance along the outer slope to micro-instability.

Also burrows with entrance along the inner slope can influence micro-instability: erosion starts at the burrow and proceeds backwards towards the outer slope.

If the entrance is located in the upper part and it doesn't have any influence to the water level (case 1 in Figure 13), the probability of micro-instability is not affected by the burrows.

As the entrance along the inner slope is placed lower, the slope of the water level inside the dike core is higher, so increasing the seepage forces and the possibility of micro-instability to occur.

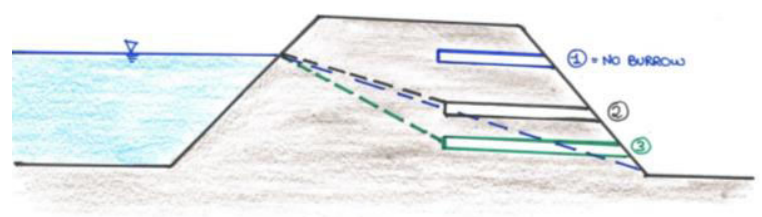

Figure 13 Influence of animal burrows with entrance along the inner slope to micro-instability.

\subsection{Summary}

Animal burrows introduce preferential flow paths and they cause heterogeneities in the dike body. For this reason, they also influence the failure mechanisms of a levee; particular attention is given to sliding of the inner slope (macro-stability), micro-instability and Internal Erosion.

First, the presence of animal burrows can cause macro-instability. The heterogeneity that they introduce, alters the phreatic surface: if it rises, the increasing water pressures causes a decrease of effective stresses. The shearing resistance is consequently reduced and, if the 
actual shear stress exceeds it, macro-instability of the inner slope occurs.

Second, the presence of animal burrows at the inner or outer slope can increase the phreatic line so that it exits at a point above the inner toe. If seepage flow develops and forces created by the flow exceed the resisting shear resistance, particles are flushed away from the soil matrix and erosion develops backwards. From that moment on, micro-instability occurs.

Third, if the water level in the river is higher than the entrance of a cavity placed along the outer slope, water flows into the entrance and fills it. If then this tunnel is connected to the inner slope, a pressure difference develops between the outer and inner exits. The seepage forces which act along the surface can erode the particles and remove the subsurface soil, so developing the mechanism of "internal erosion as evolution of defects".

The development of sliding of the inner slope, Microinstability or Internal Erosion depends on the position of the burrows and so their entrances along the slopes. Burrows placed above the water levelhave no influence on the safety, since they do not affect the water level and the reduction of weight that they introduce is negligible. Burrows located at the outer slope give a bigger effect to the three failure mechanisms as they are lower. They raise the water level and pore water pressures inside the dike body: they can lead to macro-instability, for the consequent decrease of effective stresses, and microinstability, if there is an exit point along the inner slope. Internal erosion, instead, develops when the burrow is placed below the water level and water exercises high pressures during the time required for the enlargement of the cavity. For this reason, lower burrows facilitate also internal erosion. Finally, burrows with entrance located along the inner slope can facilitate different failure mechanisms according to their position. High seepage forces can act against burrows placed near the inner toe, so facilitating micro-instability to occur: the erosion starts at the burrow and proceeds backwards. Low burrows acts as drains, so decreasing the water level and the possibility of macro-instability to occur. Contrarily, when a higher burrow intercepts the phreatic line, which flows along it, the water pressures rise, so decreasing the effective stresses and adding the water weight inside the sliding plane: macro-instability more likely occurs. Finally a burrow with exit at the inner slope and linked to the outer slope can cause internal erosion along its cavity.

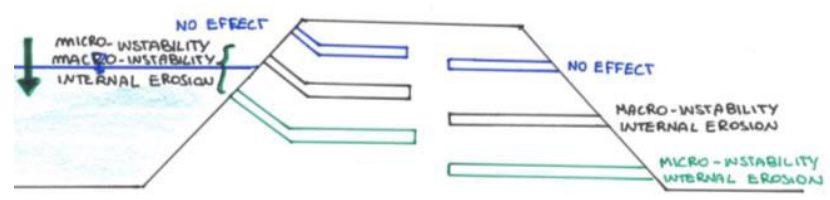

Figure 14 Influence of burrows to the failure mechanisms, according to their position along the dike.

\section{Conclusion}

The paper investigates the influence of animal burrowing on the failure mechanisms of Sliding of the Inner Slope, Micro-instability and Internal Erosion. The position of the burrows and thus their entrances along the slopes give an indication of the risk of failure. In particular, burrows located at the lower part of the outer slope are more dangerous for the failure mechanisms considered, so that special attention should be given in their identification. Internal erosion, instead, develops when the burrow is placed below the water level and when a gradient exits between the entrance and exit of the burrow. Thus, an underground network which connects the inner to the outer slope is prone to internal erosion.

These conclusions can be used in the practice in order to assess the risk of dike failure due to presence of animal burrowing activity in the dike. A first indication of the possible failure mechanisms is given by the position of the burrow entrances. Internal erosion represents a risk in case of a burrow connecting the outer to the inner slope. The risk increases as the distance between two entrances is lower and thus shorter is the tunnel connecting them. During the site investigation, it is recommended to the inspectors to walk along the dike crest and the slopes to locate the entrances of burrows. Once an entrance is recorded at the inner slope, the levee has to be carefully checked for 150-200 meters along the outer slope, in order to be able to identify potential connected underground systems.

If an underground system is not detected but still much volume has been excavated by the animals, the weakening of the whole body represents a problem to the stability of the levee. Particular attention should be given to entrances located at the outer slope, whose influence on the risk of failure increases with depth. In order to indicate the missing volume, the inspector should record the dimension, direction and depth of at least the starting tunnel.

\section{References}

1. Kruuk H. (1978). Spatial organization and territorial behaviou of the European badger (Meles Meles). $J$. Zool., 184, 1-19.

2. Byrne A. W. and al. (2012). Royal Irish Academy, The ecology of the European Badger (Meles Meles) In Ireland - a review, 112

3. Carrol P. H. (1949). Soil piping in south-eastern Arizona. United States Department of Agriculture Soil Conservation Service, Region 6, Albuquerque, New Mexico.

4. Paul D. and Slaven C. (2009). Potential failure modes of the truckee canal failure at Fernley, Nevada. Managing Our Water Retention System. Nashville, Tennessee.

5. Richards K. S. and Reddy K. R. (2007). Critical appraisal of piping phenomena in earth dam. Bullettin of Engineering Geology and the Environment, 66, 381-402. 
6. D'Alpaos L. and al. (2014). Relazione tecnicoscientifica sulle cause del collasso dell'argine del fiume Secchia avvenuto il giorno 19 gennaio 2014 presso la frazione San Matteo.

7. Taccari M.L. and van der Meij R. (2016). Investigation of the influence of animal burrowing on the failure of the levee of San Matteo along the Secchia river. E3S Web of Conferences, 2, 69579.

8. Jonkman S. N. and Schweckendiek T. (2015). FLOOD DEFENCES, Lecture Notes CIE5314. Department of Hydraulic Engineering, Faculty of Civil Engineering and Geosciences. Delft University of Technology.

9. Reddi L. N. (2003). Seepage in Soils.

10. Deltares (2012). Diagnosis of urban flood embankment performance

11. Richards K. S. and Reddy K. R. (2007). Critical appraisal of piping phenomena in earth dam. Bullettin of Engineering Geology and the Environment, 66 381-402.

12. Masannat Y. M. (1980). Development of piping erosion conditions in the Benson area, Arizona, U.S.A. Q. J. eng. Geol. London, 13, 53-61.

13. Vorogushyn S. and al. (2009). Development of dike fragility curves for piping and micro-instability breach mechanisms. Nat. Hazards Earth Syst. Sci, 9, 1383-1401

14. Heptner V. G. and Sludskii A. A. (1988). Mammals of the Soviet Union, 2

15. Nichol D. and al.(2003). Application of groundpenetrating radar to investigate the effect of badger setts on slope stability at St Asaph Bypass, North Wales. Q. J. Eng. Geol. Hydroge, 36, 143-153

16. Roper T. J. (2010). Badger

17. Coombes, M. A. \& Viles, H. A. (2015). Populationlevel zoogeomorphology: the case of the Eurasian badger (Meles Meles L.). Taylor \& Francis.

18. Bezzazi M. and al. (2010). A Simplified Analytical Modeling of the Hole Erosion Test. Am. J. Eng. Appl. Sci, 4, 765-768 